\title{
Simplified method to predict final void water levels
}

\author{
H Morgan WRM Water \& Environment, Australia
}

A Hocking $B H P$, Australia

S Henderson Henderson Geotech Pty Ltd, Australia

\begin{abstract}
At the completion of open cut coal mining, the open cut pit may remain, becoming a final void. In the majority of cases, the BHP final voids will collect water until they reach an equilibrium level where net inflows equal net outflows. BHP currently has over 100 open cut coal mine pits across Queensland and New South Wales coal operations, some of which may be final voids at closure.

A decision framework is being developed by BHP to facilitate more efficient and consistent decisions about rehabilitation of final voids. Within this framework, an understanding of the pit lake equilibrium water level is needed to assess the interaction with groundwater aquifers (whether the void will be a groundwater sink or a source of groundwater recharge) and the likelihood of discharges (overflowing) to surface waters.

At present, the most common method for predicting the final void pit lake level is to use a daily time step water balance model (WBM), often derived from complex WBMs developed for site operations. Considering the number of pits BHP needs to assess at various stages of mine planning, with frequent mine plan changes in the decades prior to closure, developing and continuously updating complex WBMs for each pit would result in inefficient closure planning.

Consequently, BHP recognised the benefit in developing a simple and efficient screening method to predict the long-term pit lake water level. To facilitate the development, a suite of daily time step WBMs were developed based on the current methodology BHP adopts to assess final voids. The aim of the WBMs was to evaluate the typical behaviour of the pit lake using a range of representative final void configurations from $a$ representative sample of seven BHP operations.
\end{abstract}

Recognising the uncertainty in the key parameters adopted in the BHP operational WBMs, a sensitivity analyses of four key parameters associated with runoff, evaporation, groundwater and spoil storage were undertaken. The results were used to guide the development of the screening method by identifying which parameters have the most influence and should therefore be accounted for in predicting the behaviour of pit lakes.

A 'pit lake prediction tool' has been developed and benchmarked to the WBM results to show confidence in the screening method. A risk assessment was included to allow effective communication of the pit lakes' risk of interacting with groundwater or spilling to the receiving environment. This pit lake prediction tool forms part of the BHP final void decision framework, which facilitates more efficient and consistent decisions about rehabilitation of final voids.

Keywords: water balance model, final voids, mine closure, pit lake

\section{Introduction}

At the completion of open cut coal mining, an open cut pit may remain, becoming a final void. In the majority of cases, BHP final voids will collect water until they reach an equilibrium level where net inflows equal net outflows. The water stored within final voids is referred to as the final void 'pit lake'. BHP currently has over 100 open cut coal mine pits across Queensland (QId) and New South Wales (NSW) coal operations, some of which may be final voids at closure. 
A decision framework is being developed by BHP to facilitate more efficient and consistent decisions about rehabilitation of final voids. Within this framework, an understanding of the pit lake equilibrium, or longterm water level is needed to assess the interaction with groundwater aquifers (whether the void will be a groundwater sink or a source of groundwater recharge) and discharges (overflowing) to surface waters. It is also important for the assessment of the geotechnical stability of the highwall and endwall and to make decisions about potential use of the final void and pit lake.

At present, the most common method adopted by BHP and the coal mining industry in eastern Australia for predicting the final void pit lake level is to use a daily time step water balance model (WBM), often derived from complex WBMs developed for site operations. Considering the number of pits BHP needs to assess at various stages of mine planning, with frequent mine plan changes in the decades prior to closure, developing and continuously updating complex WBMs for each pit would result in inefficient closure planning.

Consequently, BHP recognised the benefit in developing a simple and efficient screening method to predict a pit lake water level. To facilitate the development, a suite of daily time step WBMs were developed based on the current methodology BHP adopts to assess final voids. The aim of the WBMs was to evaluate the typical behaviour of the pit lake using a range of representative final void configurations from a representative sample of seven BHP operations.

To develop the screening method, an understanding of the pit lake behaviour needed to be established, including the equilibrium water level and fluctuations in water level due to wet/dry periods. A suite of daily timestep WBMs were developed to assess the pit lake water level behaviour for a representative range of final void configurations across seven BHP operations. A sensitivity analysis was then undertaken to assess the impact of uncertainty in key parameters adopted in existing BHP operational and final void WBMs. Understanding how these parameters effect pit lake water level informed development of the screening method. The parameters assessed were:

- Evaporation pan factor.

- Australian Water Balance Model (AWBM) runoff parameters.

- Groundwater inflow rates.

- In-pit dumped spoil (waste rock) storage (porosity).

Based on the results of the WBM and the sensitivity analyses, a screening tool was developed. The screening tool, referred to as the 'pit lake prediction tool' uses an annual average balance of rainfall/runoff and evaporation to predict the equilibrium water level. Benchmarking of the pit lake prediction tool results to the WBM results gives confidence that the screening method is effective at predicting the risk of interaction with groundwater and discharges to surface waters.

This paper presents the results of daily timestep WBMs, which were used to assess pit lake behaviour and conduct a sensitivity analysis. How these results are adopted within the screening method is also discussed. The screening method and risk assessment is then presented and benchmarked to the BHP daily time step WBM results.

\section{$2 \quad$ Daily timestep water balance modelling}

\subsection{Pit lake behaviour}

To evaluate the pit lake water level behaviour, a daily timestep WBM was developed by Hydro Engineering Consultancy (HEC 2018) for BHP in the GoldSim dashboard player format (GoldSim 2017). A final 21 void configurations were assessed for Qld (18) and NSW (3) open cut coal mining operations. These included current mining pits (relevant in the instance of an unplanned closure), and life of asset (LOA) final voids.

The voids ranged in size (total storage capacities (based on final void stage storage curves) from 6-600 GL), geometry and catchment areas (from 50-1,500 ha). For all cases it was assumed mine rehabilitation was 
completed, that is, that all spoil emplacements were vegetated. The final void highwall, endwall and the mined coal floor were not rehabilitated.

\subsubsection{Methodology}

Figure 1 is an example daily time step WBM pit lake water level plot. Water level plots are the current BHP method for communicating final void risk internally and externally to regulators for final void assessments. The equilibrium water level occurs once the long-term trend in water levels is no longer increasing. For this assessment, the WBM was run for two 128 year climate cycles (total 256 years). Calculation of the equilibrium water level occurred from the start of the second climate cycle, after the final void had reached equilibrium. The equilibrium water level is the mean water level over this period.

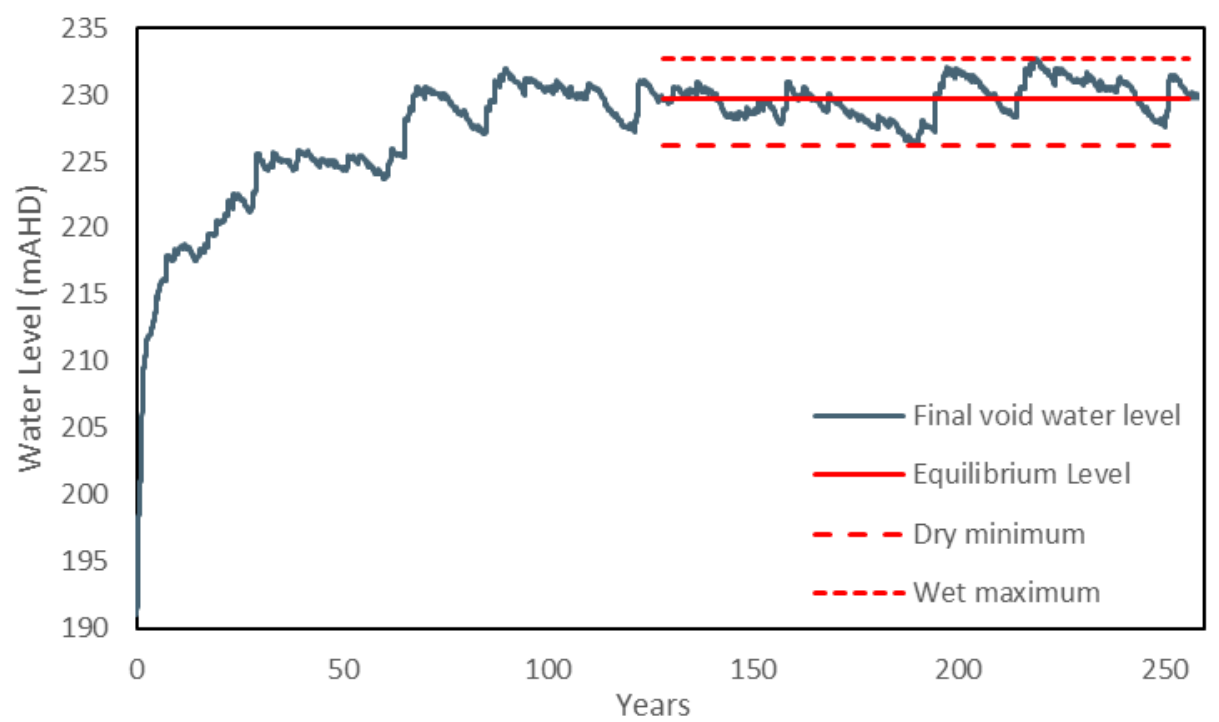

Figure 1 Example daily time step water balance model predicted final void water level

Once the equilibrium water level was established, the fluctuation in water level from wet maximum and dry minimum was determined. Fluctuations in water level are not purely seasonal but rather cycle over multiple years. Assessing the behaviour of the pit lake focused on the equilibrium water level and the range of wet/dry fluctuations.

Modelling of climate change was not included in the scope of this study. Climate change projections for central Queensland indicates a net increase in evaporation (Commonwealth Scientific and Industrial Research Organisation (CSIRO) 2015). A net increase in evaporation would result in a lower equilibrium water level. However, it is possible that the wet/dry fluctuations may be affected by greater variability.

\subsubsection{Results and discussion}

Figure 2 shows the fluctuation in pit lake water level for the 21 final voids using the daily timestep WBM, normalised by setting the equilibrium water level to zero. Normalising the equilibrium water level allows for direct comparison of water levels which vary in elevation across the 21 voids. The results show the typical fluctuation is about $\pm 5 \mathrm{~m}$.

Pit 1 , which is the largest void in total storage volume has a similar range of fluctuation as Pit 8 , which is the smallest void. The results suggest the size of the final void is not a factor in the fluctuations in water level.

Subsequently, a conservative wet/dry fluctuation of $\pm 10 \mathrm{~m}$ was adopted for the screening method, to account for the full range of wet/dry fluctuations shown in Figure 2. 


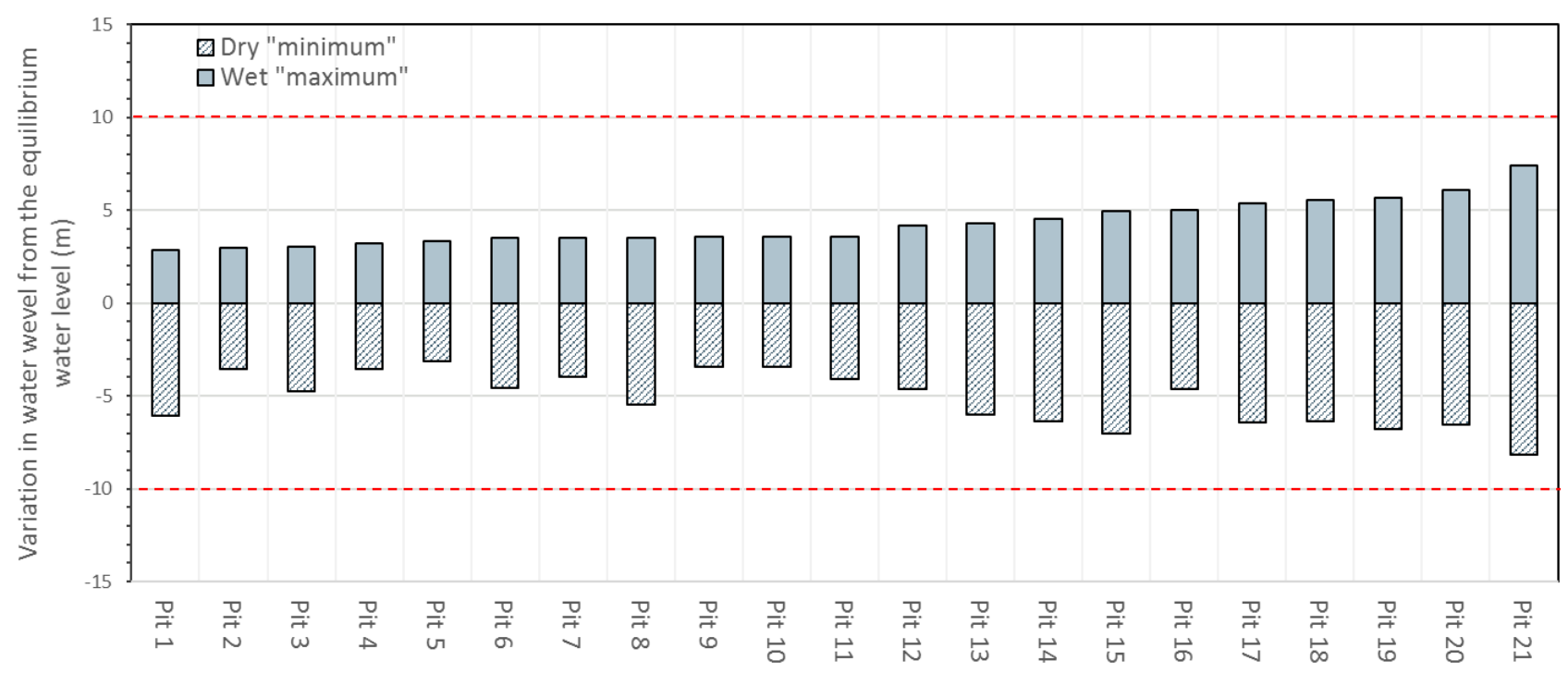

Figure 2 Fluctuations in water level from the equilibrium pit lake water level

\subsection{Sensitivity analysis}

A sensitivity analysis was undertaken to identify which parameters were important to incorporate into the screening method. The sensitivity analysis compared three configurations of a final void from its current footprint to the LOA footprint. It was assumed groundwater inflows and the water table/recharge elevation were the same, due to lack of groundwater information. The three voids varied in size, with total storage capacity ranging from $14,000 \mathrm{ML}$ to $150,000 \mathrm{ML}$ and total catchment area from 124 ha to 578 ha.

The WBM used the 'base case' parameters for each assessment (defined in later sections), based on the BHP operational WBMs which have been developed for a variety internal studies from different consultants. For each sensitivity analysis, three of the four parameters assessed were held constant at the 'base case' value. The parameters assessed include:

1. Evaporation pan factor.

2. AWBM runoff parameters.

3. Groundwater inflow rates.

4. In-pit dumped spoil (waste rock) storage (porosity).

The GoldSim dashboard gave the user the ability to change some parameters manually, while others were preset. Normalising results by setting the base case equilibrium water levels to zero allowed comparison of the impact to the pit lake behaviour from the sensitivity analysis.

\subsubsection{Pan factor sensitivity analysis methodology}

Evaporation from the pit lake is generally assumed to be lower than evaporation from a water body at natural surface due to the depth of the pit lake surface below natural surface (McJannet et al. 2017). A pan factor is applied to the daily pan evaporation to account for this reduction in evaporation from the pit lake. Evaporation from final voids is expected to be affected by the void alignment, geometry and depth via the following mechanisms:

- Shading of the pit lake (McJannet et al. 2017).

- Wind speed at the water level which could result in a change in humidity at the pit lake surface.

However, it is uncertain how much impact the variation in these mechanisms have on evaporation. 
Studies of evaporation from pit lakes in Australia have adopted pan factors of 0.7 (Worley Parsons 2013). BHP adopts a pan factor of 0.75 in operational WBMs. The pan factor is assumed to be constant for all water levels. Some studies suggest that this simple approach may not be accurate (Mulder 1997; McJannet et al. 2017). Field studies are underway to develop improved estimates for evaporation in pit lakes. However, the constant pan factor assumption reflects current practice and the GoldSim dashboard only allowed increase and decrease in the constant pan factor.

The sensitivity analysis compared a range of pan factors including $0.55,0.65$ and 0.85 . Changing the pan factor by \pm 0.1 changed evaporation by about $\pm 13 \%$ compared to the base case.

Salinity of a water body is known to reduce evaporation as salinity increases by about $1 \%$ per $10,000 \mu \mathrm{s} / \mathrm{cm}$ (Calder \& Neal 1984). This affect would be relatively small compared to other factors. Salinity was not included in the scope of this study.

\subsubsection{Pan factor results and discussion}

Figure 3 shows the change in behaviour of the pit lake water level for the pan factor sensitivity analysis. Changes to pan factor had a negligible impact on the wet/dry fluctuation in water level for Pit A and Pit B, but some impact for Pit C. As the pan factor decreased, the fluctuations decreased. Changes to pan factor had a significant impact on the equilibrium water level, the largest impact of the four parameters assessed.

BHP is currently undertaking a study in partnership with CSIRO to measure and model evaporation from open cut coal mine pit lakes. Therefore, the screening tool has adopted the base case value, until the findings of the CSRIO study can be incorporated.

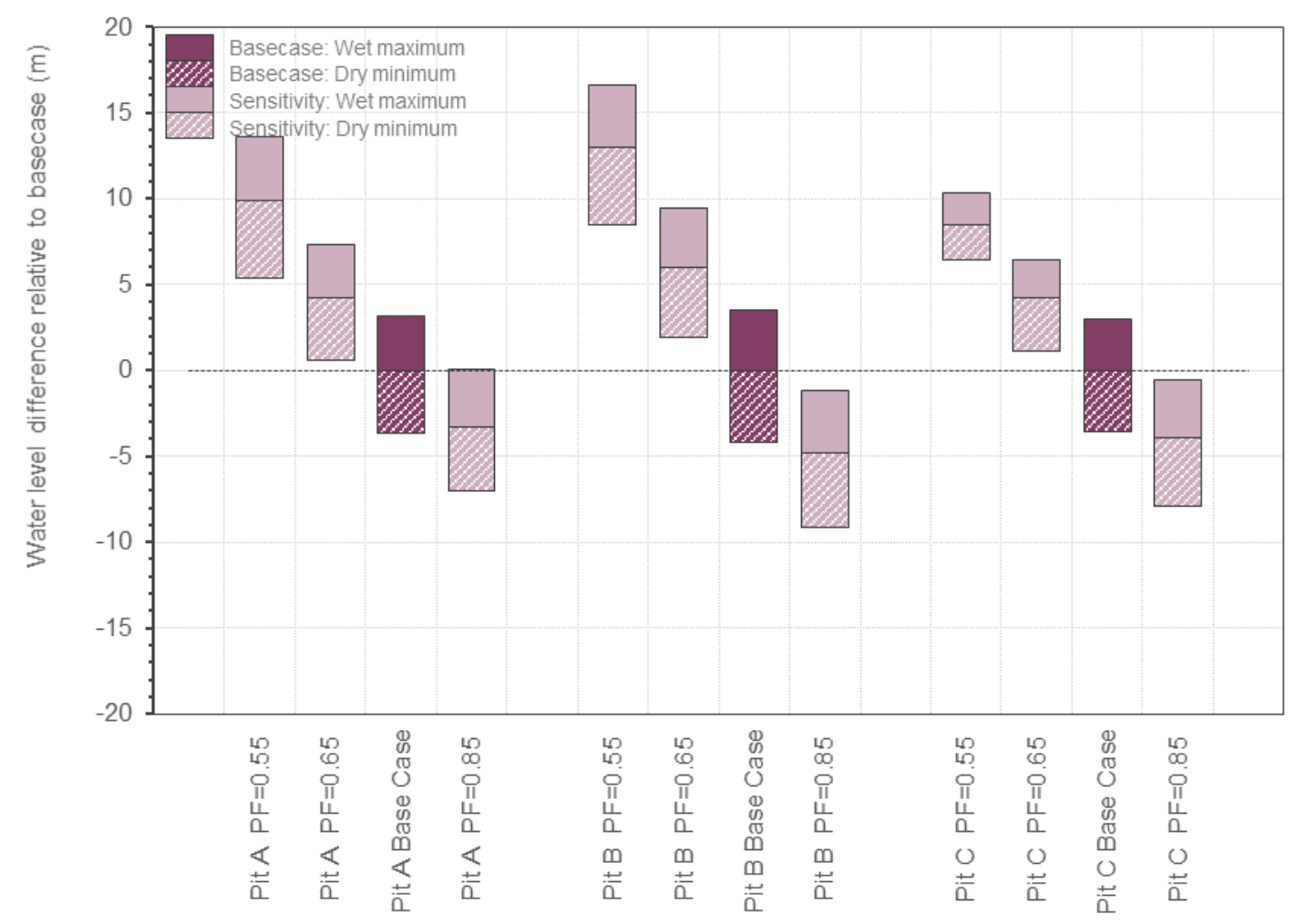

Figure 3 Pan factor sensitivity analyses results compared to the base case

\subsubsection{Australian Water Balance Model runoff parameter sensitivity analysis methodology}

The daily timestep WBM uses the AWBM runoff parameters to calculate the depth of runoff generated from a rain event (Boughton 2004). AWBM parameters estimate runoff depth for a unit area of each land use type. AWBM parameters are climate dependant; therefore, the same AWBM parameters will produce different results in different climates. For the sensitivity analysis, the climate data was based on Moranbah in central 
Queensland (The Department of Environment and Science (DES) 2018), as this location is representative and central to the BHP mines assessed. The AWBM parameters affect runoff in the following ways:

- The soil moisture capacity $(C)$ affects the depth of runoff from a rainfall event.

- The baseflow index (BFI) represents the portion of runoff that is baseflow.

- The baseflow constant $(\mathrm{Kb})$ and surface flow recession constant (Ks) affect the attenuation of runoff, or the timing.

The annual average runoff coefficient $\left(C_{v}\right)$ is calculated from the WBM results. $C_{v}$ is the percentage of rain that is converted to runoff over the simulation period for each land use. Baseflow is an important factor for final void WBMs, as there are often large catchments of in-pit spoil where only baseflow is reporting to the final void while surface runoff flows away from the void.

The AWBM parameters adopted were based on calibrated BHP operational WBMs. For the sensitivity analysis, the GoldSim dashboard allowed only the soil moisture capacity to be varied by $\pm 20 \%$ through three preset scenarios (base case, AWBM high runoff and AWBM low runoff). That is, the user was not able to adjust AWBMs beyond this range for this study.

Table 1 shows the variation in $C_{v}$ for each land use from changing the soil moisture capacity. Land uses with a high $C_{v}$ (pit, hardstand) have low soil moisture capacity, so changes of $\pm 20 \%$ have a small effect compared to land uses with a low $\mathrm{C}_{v}$ and a high soil moisture content (rehabilitated spoil and spoil). For the AWBM low, $C_{v}$ decreased by $5 \%$ to $18 \%$ and for the AWBM high, $C_{v}$ increased by $6 \%$ to $27 \%$ for each land use.

Table 1 Average annual runoff coefficient $\left(C_{v}\right)$ and the baseflow constant $(\mathrm{Kb})$ for final land use

\begin{tabular}{lcccccc}
\hline Land use & Surface flow $\left(\mathbf{C}_{\mathbf{v}}\right)$ & Baseflow $\left(\mathbf{C}_{\mathbf{v}}\right)$ & Kb & Base case & AWBM high & AWBM low \\
\hline Spoil & $1.5 \%$ & $5.9 \%$ & 0.8 & $7.3 \%$ & $9.3 \%$ & $6.0 \%$ \\
Natural & $6.5 \%$ & $1.1 \%$ & 0.15 & $7.6 \%$ & $9.1 \%$ & $6.5 \%$ \\
Rehabilitated spoil & $7.4 \%$ & $2.1 \%$ & 0.22 & $9.5 \%$ & $11.7 \%$ & $7.9 \%$ \\
Mining pit & $27.2 \%$ & $3.1 \%$ & 0.1 & $30.3 \%$ & $34.2 \%$ & $27.1 \%$ \\
Hardstand & $42.5 \%$ & $0.0 \%$ & 0 & $42.5 \%$ & $45.1 \%$ & $40.3 \%$ \\
\hline
\end{tabular}

AWBM - Australian Water Balance Model.

\subsubsection{Australian Water Balance Model runoff parameter results and discussion}

Figure 4 shows the change in behaviour of the pit lake water level for the AWBM sensitivity analysis compared to the base case. Changes to AWBM runoff coefficients had a negligible impact on the wet dry fluctuation in water level. However, they did have an impact on the equilibrium water level. Table 1 shows there was a larger percentage change in the AWBM high than the AWBM low from the base case, which explains the slightly larger water level change for the AWBM high scenario.

There was concern that the relatively low impact on water levels was due to range restrictions in the model rather than reflecting the impact of runoff in real voids. Consequently, the AWBM base case runoff coefficients were benchmarked to AWBM parameter values from 15 WBMs from internal studies produced by a variety of consultants. The studies were based on operational open cut coal mines within the Bowen Basin Qld. The annual average runoff coefficient $\left(C_{v}\right)$ for the 15 AWBM parameters was calculated using the same rainfall and evaporation data as the BHP WBMs.

Figure 5 shows the benchmarking of four land use types (natural, rehabilitated spoil, spoil and mining pit). The results indicate there is a much larger range in $C_{v}$ values than was assessed in this study, with variations of up to an order of magnitude for spoil. This benchmarking of AWBM runoff parameters highlighted significant variability between different studies. 


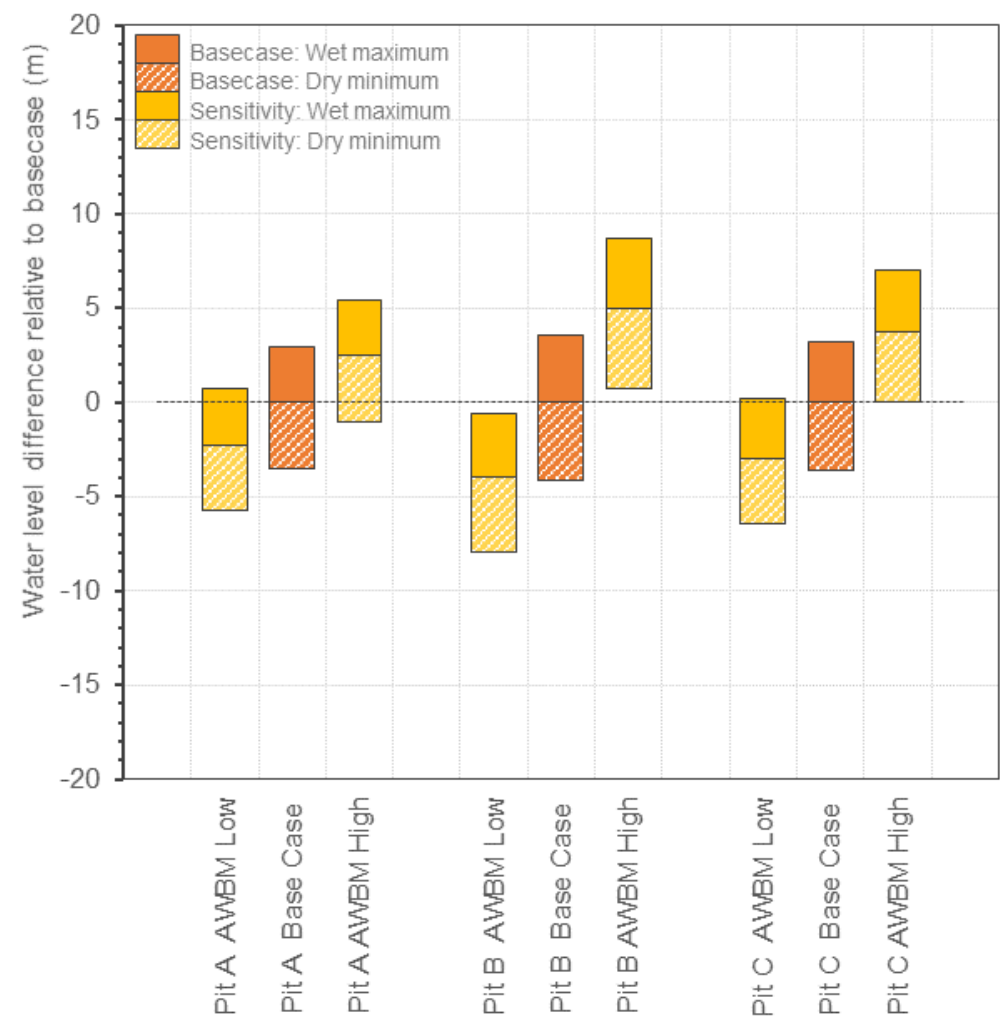

Figure 4 Australian Water Balance Model sensitivity results compared to the base case

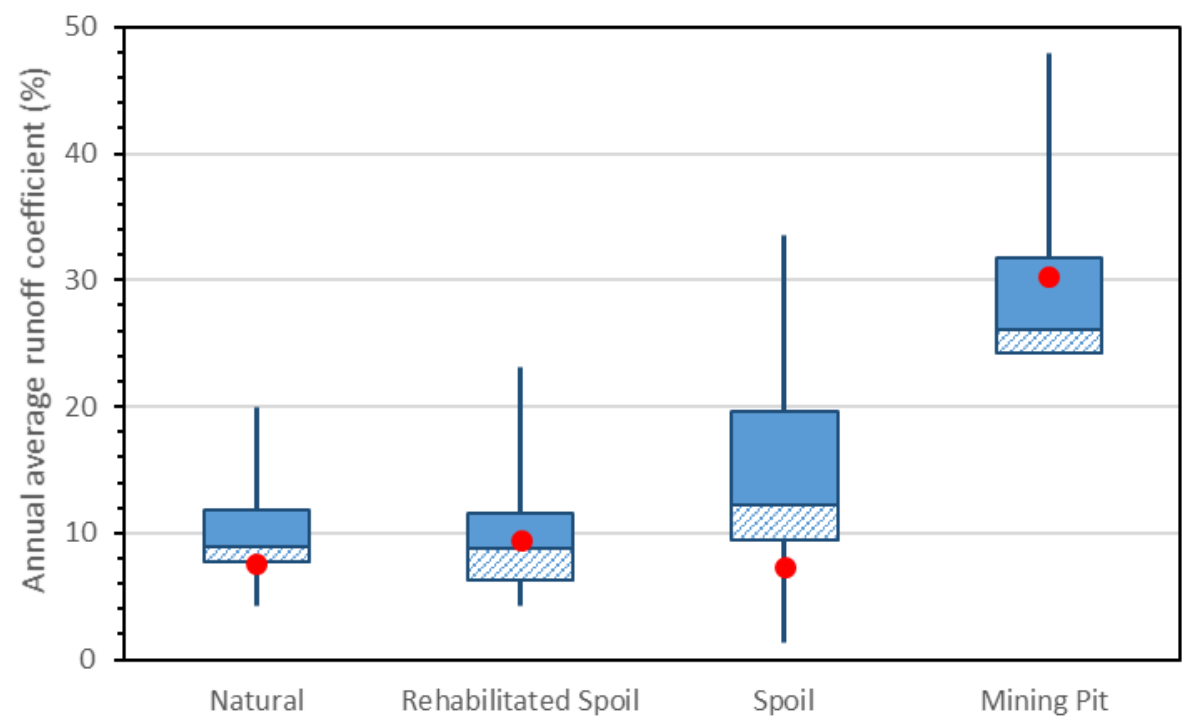

Figure 5 Benchmarking of industry $C_{v}$ compared to the BHP Qld final void water balance model

The base case AWBMs were adopted in the screening tool. However, the benchmarking highlights the need for further work to better define final void AWBMs. This could be achieved through more detailed calibration of the AWBM runoff parameters that have the largest contribution of runoff to BHP final voids, namely, 'pit' and 'rehabilitated spoil'.

\subsubsection{Groundwater inflow sensitivity analysis methodology}

The WBM was based on the assumption of the principal source of groundwater being the coal seam at the base of the void. This is an appropriate assumption for the environmental setting of the pits in this study based on internal groundwater studies for BHP coal mines, but may not be broadly applicable to other 
environmental settings. Based on our current understanding about the groundwater behaviour, it was assumed the inflow rate varied linearly from a maximum when the pit was empty to zero when the pit lake level was at the background water table level.

If the equilibrium water level is above the water table (recharge level), the void is recharging the aquifer. The WBM treated recharge in similar manner as groundwater inflow, that is, with the recharge outflow rate is based on the depth of water above the recharge level.

The GoldSim dashboard did not allow for this depth/rate relationship to be changed. However, the inflow rate and recharge level could be changed. Consequently, the inflow depth/rate relationship means groundwater reduces to zero as the pit lake water level approaches the recharge level. Therefore, rainfall/runoff is the only mechanism allowing the water level to reach and exceed the recharge level.

The base case inflow rate was $0.22 \mathrm{ML} /$ day at the pit floor for the three final voids, which was based on groundwater modelling or from operational WBMs. In addition to the base case, the inflow rates of $0 \mathrm{ML} /$ day, $0.44 \mathrm{ML} /$ day and $2.5 \mathrm{ML} /$ day were assessed. Because of the difficulty in estimating groundwater inflows to pits, there is a relatively high uncertainty in the rate and this is reflected in the large range selected for the sensitivity analysis. The recharge level was the same elevation for each of the three voids and was between $56 \mathrm{~m}$ and $146 \mathrm{~m}$ above the pit floor. Estimated groundwater inflow rates ranged from 0.04 to $0.6 \mathrm{ML} /$ day across the seven BHP operations, so the inflow rate for these particular pits was quite typical.

\subsubsection{Groundwater inflow sensitivity analysis results and discussion}

Figure 6 shows the change in behaviour of the pit lake water level for the groundwater inflow rate sensitivity analysis compared to the base case. Changes to inflow rate had some influence on the wet/dry fluctuations, with higher rates resulting in less fluctuation. The equilibrium water level appeared to be more sensitive for small voids (Pit A) compared to the two large voids.

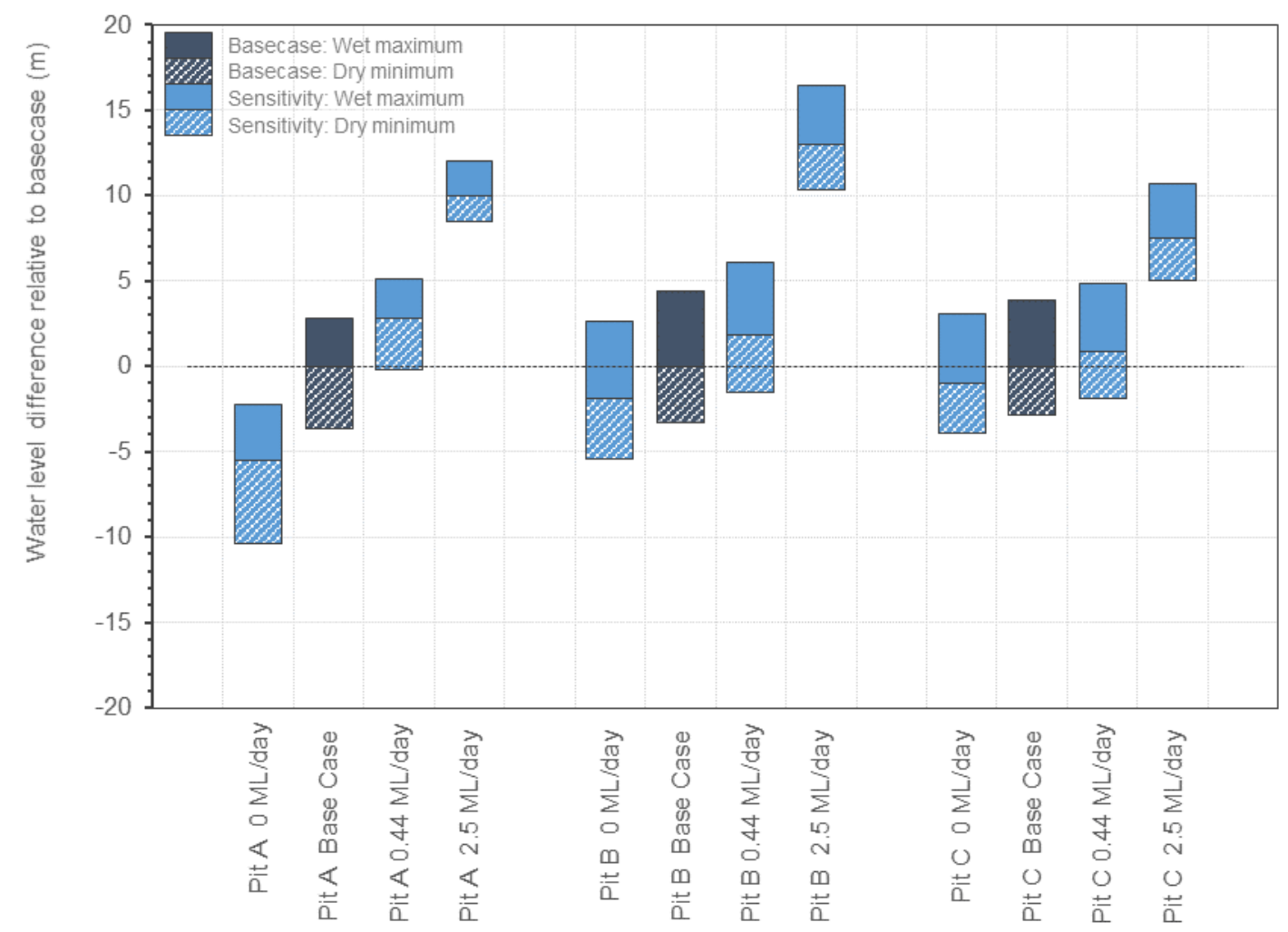

Figure 6 Groundwater inflow rate sensitivity analyses results compared to the base case 
The results show that a range of uncertainty of $\pm 100 \%$ in groundwater inflow rate did not have a large impact on the equilibrium water level for the pits evaluated. Based on the results shown in Figure 6 , the range of uncertainty needs to be an order of magnitude to have a large impact on the equilibrium water levels.

Based on internal groundwater studies, the current assumption is groundwater inflow will reduce to zero as the pit lake water level approaches the recharge level. This is based on the principle source of water being the coal seam at the base of the pit. Therefore, as the depth of water in the pit increase, the head drive for groundwater inflows decreases, when the water level in the pit reaches the recharge level, there is no head drive for groundwater inflows. Therefore, groundwater will not contribute to the pit lake recharging or spilling.

The mechanisms which contributes to the pit lake spilling or recharging is rainfall/runoff and evaporation. This would not be the case if a constant inflow rate, or the source of the groundwater was not at the base of the pit. Therefore, groundwater was not incorporated into the screening tool and benchmarking to WBM results, presented in Section 3.2, supports this.

\subsubsection{In-pit spoil storage (porosity) sensitivity analysis methodology}

In open cut strip mining the coal mine's spoil (waste rock) is progressively dumped behind the current pit as the mine progresses. For final voids, this in-pit spoil stores water when the spoil is below the final void water level. The volume of water that can be stored is related to spoil porosity, that is, the percentage of the spoil volume that is 'open space'.

The spoil storage stage storage curve was added to the final void stage storage curve. Therefore, for each metre of elevation change, the stage storage curve had a larger volume of water than for the final void only stage storage curve.

Spoil from open cut coal mines (truck and shovel) tends to bulk by approximately $20 \%$ on excavation, resulting in a porosity of about $25 \%$. As the spoil settles, this will decrease to $10 \%$ to $20 \%$ over the long-term (Hawkins 2004). This is likely higher than the in situ material. The 'base case' porosity (P) adopted for final voids was $10 \%$. The sensitivity analysis of spoil porosity assessed three additional values ( $0 \%, 20 \%$ and $30 \%)$.

\subsubsection{In-pit spoil storage (porosity) sensitivity analysis results and discussion}

Figure 7 shows the change in behaviour of the pit lake water level for the changes in spoil storage compared to the base case. Increasing the spoil storage reduced the wet/dry fluctuations. In addition, it appeared to cause a small reduction in the equilibrium water level as porosity increased.

The results show that spoil storage does not need to be considered in the screening tool to predict the behaviour of pit lake water level. However, spoil storage would need to be considered for calculating the total storage inventory at the equilibrium water level.

\subsection{Sensitivity analysis summary}

With regard to equilibrium water level, the sensitivity analysis undertaken found that:

- AWBM changes of about $\pm 20 \%$ produced changes of up to \pm 4 to $5 \mathrm{~m}$.

- Pan factor changes of \pm 0.1 ( $\pm 13 \%$ total change) produced changes of up to \pm 5 to $6 \mathrm{~m}$.

- Groundwater inflow rate change of $\pm 100 \%$ produced changes of up to \pm 3 to $6 \mathrm{~m}$.

- Porosity changes of $\pm 10 \%$ ( $\pm 100 \%$ total change) produced changes of up to \pm 0 to $2 \mathrm{~m}$.

These results show that evaporation and AWBM parameters have the most impact on pit lake behaviour, with respect to the equilibrium water level. If there was uncertainty of more than $100 \%$ for groundwater inflows, this could have a large impact. 


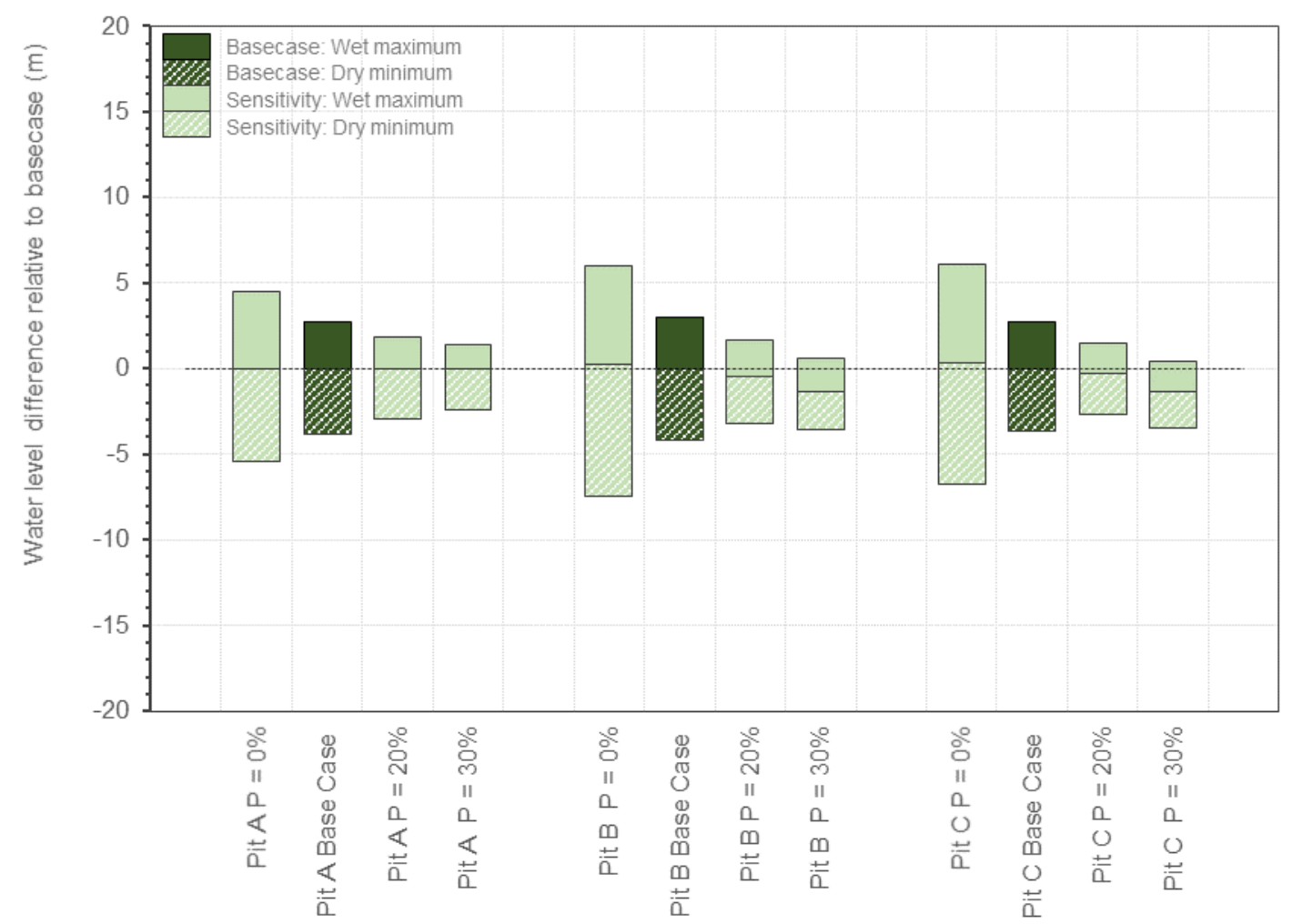

Figure $7 \quad$ In-pit spoil storage (porosity) sensitivity analyses results compared to the base case

Wet/dry fluctuations are sensitive to changes in spoil storage, and to a small degree to groundwater inflow rate. Groundwater and porosity were not included in the screening tool. However, based on the sensitivity results they were adequately accommodated in the adopted wet/dry fluctuation of $\pm 10 \mathrm{~m}$.

\section{Pit lake prediction tool}

Base case modelling of the 21 final voids and the sensitivity analysis using a daily timestep WBM found that final voids consistently fluctuate around an equilibrium level. The equilibrium water level is the average water level when the final void is in long-term balance with inflows and outflows. Therefore, it was hypothesised that an annual average balance could predict the behaviour of a pit lake as effectively as a daily timestep WBM. A screening method was developed to predict the pit lake equilibrium water level using annual average values for the key input parameters.

\subsection{Methodology}

The pit lake prediction tool is an annual average rainfall/runoff and evaporation water balance that adopts the same base case parameters used in the WBM. Groundwater was excluded from the pit lake prediction tool. The sensitivity analysis showed the typical groundwater inflow rates considered in this study, and the assumption that the coal seam at the base of the void is the principle source of groundwater had little impact on the equilibrium water level. However, it could be added if required later for different groundwater conditions. Porosity (spoil storage) was included $(P=10 \%)$ for calculating the final void total storage inventory.

A WBM calculates runoff on a daily time step for each land use. Therefore, the AWBM annual average runoff coefficient $\left(C_{v}\right)$ was adapted to use as an annual average for each catchment, referred to as the catchment runoff coefficient $\left(\mathrm{CC}_{\mathrm{v}}\right) . \mathrm{CC}_{\mathrm{v}}$ accounts for both surface runoff and baseflow (surface flow and baseflow $\mathrm{C}_{\mathrm{v}}$ are shown in Table 1). 
$\mathrm{CC}_{v}$ is a weighted average $\mathrm{C}_{v}$ for the different land use portions of the catchment, shown in Table 2 for the three final voids. The majority of the runoff for the final voids assessed came from 'rehabilitated spoil' and 'mining pit' land uses.

Table 2 Catchment runoff coefficient $\left(C_{v}\right)$

\begin{tabular}{lccccccccc}
\hline & \multicolumn{3}{c}{$\begin{array}{c}\text { Surface catchment } \\
\text { (ha) }\end{array}$} & \multicolumn{3}{c}{$\begin{array}{c}\text { Baseflow catchment } \\
\text { (ha) }\end{array}$} & \multicolumn{3}{c}{$\begin{array}{c}\text { Catchment runoff coefficient } \\
\text { (CC) }\end{array}$} \\
& Pit A & Pit B & Pit C & Pit A & Pit B & Pit C & Pit A & Pit B & Pit C \\
\hline Spoil & 0 & 0 & 0 & 0 & 0 & 0 & $0.0 \%$ & $0.0 \%$ & $0.0 \%$ \\
Natural & 4 & 34 & 28 & 4 & 34 & 28 & $0.2 \%$ & $0.4 \%$ & $0.3 \%$ \\
Rehabilitated spoil & 89 & 472 & 487 & 124 & 853 & 881 & $6.9 \%$ & $7.9 \%$ & $8.2 \%$ \\
Mining pit & 30 & 62 & 47 & 30 & 62 & 47 & $7.1 \%$ & $3.1 \%$ & $2.4 \%$ \\
Hardstand & 2 & 11 & 11 & 2 & 11 & 11 & $0.6 \%$ & $0.8 \%$ & $0.8 \%$ \\
Total & 124 & 578 & 573 & 160 & 959 & 967 & $14.9 \%$ & $12.2 \%$ & $11.7 \%$ \\
\hline
\end{tabular}

The equilibrium water level is calculated in the following steps.

Step one calculates the annual average runoff volume (ARV) to the final void using Equation 1 . The total catchment area equals the surface catchment, as the additional area in the baseflow catchment is accounted for in the calculation of $\mathrm{CC}_{\mathrm{v}}$.

$$
A R V\left(\mathrm{~m}^{3}\right)=\text { Total catchment area }(\mathrm{ha}) * R D(\mathrm{~mm}) * C C_{v} * 10
$$

Step two calculates the net annual average evaporation (NPE) depth shown in Equation 2. NPE is the pan evaporation (PE) multiplied by the pan factor (PF) minus annual average annual direct rainfall (RD).

$$
N P E(m m)=(P E(m m) * P F)-R D(m m)
$$

Step three calculates the surface area required to evaporate the annual runoff volume using Equation 3 . This is the surface area of the final void at the equilibrium water level.

$$
\text { Equilibrium surface area }(\mathrm{ha})=A R V\left(\mathrm{~m}^{2}\right) \div N P E(\mathrm{~mm}) \div 10,000,000
$$

Step four uses the final void stage storage curve to calculate the pit lake equilibrium water level from the equilibrium surface area.

Step five is to assess the risk of the pit lake recharging or spilling. The wet maximum water level is added $(+10 \mathrm{~m})$ to the equilibrium water level and the 'depth below recharge' and the 'depth below spill' is calculated from this.

To communicate to stakeholders and regulators the risk of a particular final void interacting with groundwater and spilling, the depth of rain required to make the final void recharge or spill from the wet maximum water level is estimated. $100 \%$ runoff coefficient and no evaporation are assumed for this calculation.

If the depth of rain required to make the final void recharge or spill is greater than $1,000 \mathrm{~mm}$, the risk of interaction is considered to be very low. For comparison, the 7 day $0.05 \%(1$ in 2,000) annual exceedance probability (AEP) rainfall total for Moranbah is $650 \mathrm{~mm}$ and the 4 day probable maximum precipitation (PMP) is about 1,500 mm (Ball et al. 2016). Therefore, 1,000 mm represents an extreme event.

\subsection{Results and discussion}

Table 3 shows the pit lake prediction tool results for the three final voids assessed in the sensitivity analyses. The pit lake prediction tool predicted equilibrium water levels within 1 to $2 \mathrm{~m}$ of the daily time step WBM. 
Table 3 Pit lake prediction tool

\begin{tabular}{lcccc}
\hline & Unit & Pit A & Pit B & Pit C \\
\hline Annual average runoff volume & $\mathrm{m}^{3}$ & 109,000 & 418,500 & 398,900 \\
Equilibrium pit lake surface area & ha & 11.9 & 45.5 & 43.4 \\
Predicted equilibrium water level & mAHD & 229 & 201 & 218 \\
WBM equilibrium water level & mAHD & 230 & 199 & 216 \\
\hline WBM - water balance model. & & & &
\end{tabular}

The predicted equilibrium water level of the 21 final voids was benchmarked against the WBM results. Figure 8 shows the comparison of modelled and predicted results as depth below crest. The following are of note:

- The two data points that are above the trend line were recharging in the daily time step WBM (water was leaving (seeping from) the final void), therefore the pit lake prediction tool has predicted a higher water level by ignoring loss to groundwater recharge.

- The water levels predicted by the pit lake prediction tool, have equilibrium water levels within \pm 3 to $6 \mathrm{~m}$ of the WBM, excluding the two recharging voids.

Table 4 shows the pit lake prediction tool risk assessment for the three final voids. Pit $\mathrm{A}$ wet maximum water level (equilibrium water level $+10 \mathrm{~m}$ ) is $7 \mathrm{~m}$ below the recharge level, however $1,400 \mathrm{~mm}$ of rain from a single event would be required for the water level to reach the recharge level. The depth of rain required for the final voids to spill (overflowing) would be greater than $8,000 \mathrm{~mm}$. Applying the 1,000 $\mathrm{mm}$ screening tool trigger discussed previously indicates the three final voids have a very low risk of recharge or spilling. Therefore, they would be a low priority for detailed assessment.

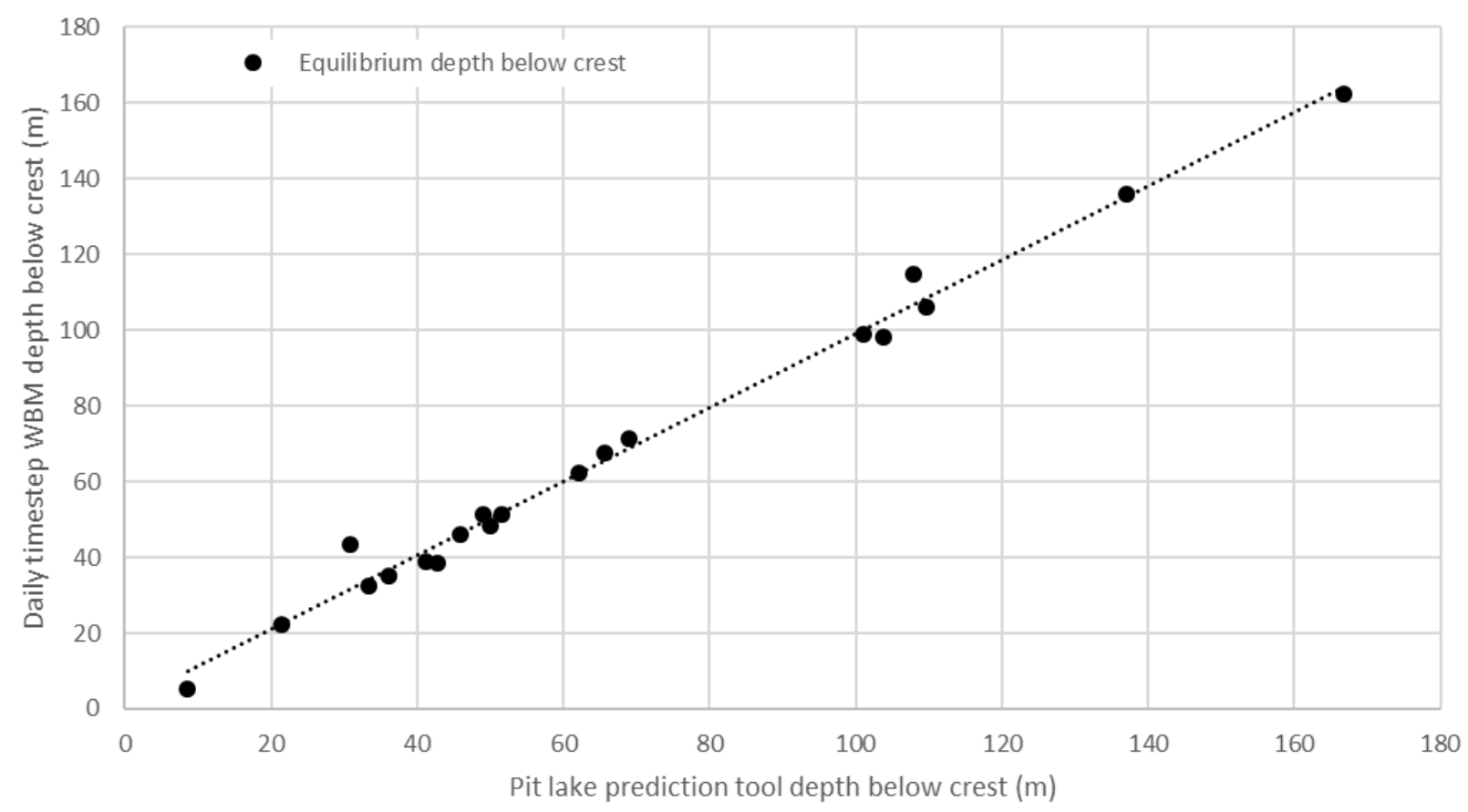

Figure 8 Comparison between the daily timestep water balance model and pit lake prediction tool equilibrium water levels 
Table 4 Pit lake prediction tool risk assessment

\begin{tabular}{lcccc}
\hline & Unit & Pit A & Pit B & Pit C \\
\hline Equilibrium water level & mAHD & 229 & 201 & 218 \\
Wet maximum water level & mAHD & 239 & 211 & 228 \\
Wet maximum depth below recharge & $\mathrm{m}$ & 7.0 & 35 & 18 \\
Rain event depth to reach recharge & $\mathrm{m}$ & 1.4 & 15 & 12 \\
Risk of recharge & & Very low & Very low & Very low \\
Wet maximum depth below crest & $\mathrm{m}$ & 23 & 59 & 39 \\
Rain event depth to reach spill & $\mathrm{m}$ & 8.7 & 24 & 19 \\
Risk of spilling & & Very low & Very low & Very low \\
\hline
\end{tabular}

The pit lake prediction tool could be revised to add a constant groundwater inflow rate if required, by calculating the additional surface area needed to evaporate the annual groundwater inflow. For example, a constant inflow rate of $0.22 \mathrm{ML} /$ day ( $80 \mathrm{ML}$ p.a.) would increase the equilibrium pit lake area by about 9 ha. Equilibrium water levels in the three final voids assessed would be increased by 6 to $12 \mathrm{~m}$ if a constant inflow was adopted. This would result in Pit A being at risk of recharge, which would trigger on the BHP final void decision framework for further detailed assessment.

Figure 9 shows the predicted rain depth required to make the 21 final voids recharge and spill, from the wet maximum water level predicted using the pit lake prediction tool. It is apparent that for the majority of voids, the depth of rain required is above the $1,000 \mathrm{~mm}$ trigger for both scenarios and therefore the risk of recharging or spilling is very low.

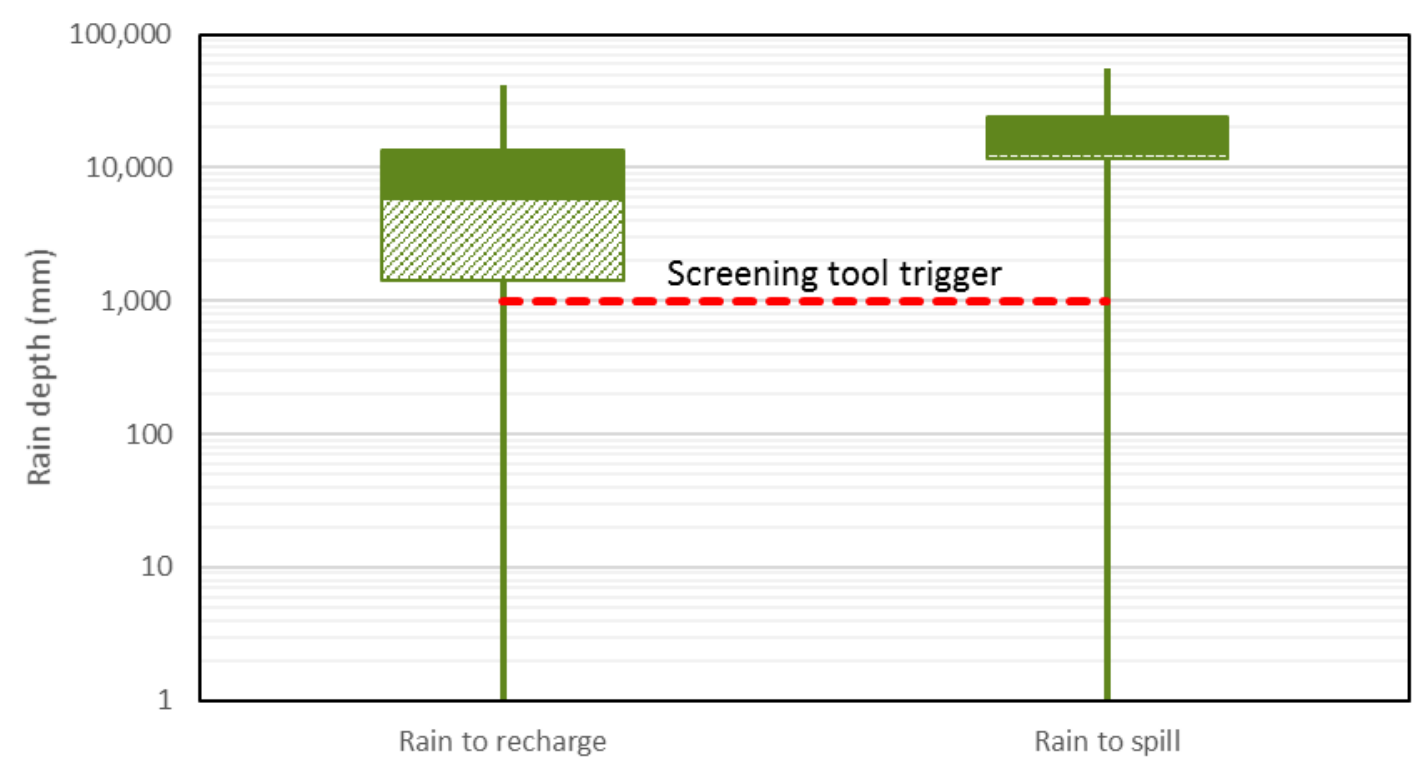

Figure 9 Depth of rain required for final voids to spill or recharge

A daily timestep WBM over 256 years generates about 94,000 cells of data, which are processed to determine the equilibrium and maximum water level. The pit lake prediction tool can achieve the same in eight cells of data, as well as assessing the risk of interacting with groundwater or spilling from an extreme rain event. Adoption of the pit lake prediction tool has resulted in a simple and efficient method for screening the likely interaction with groundwater aquifers and discharges to surface waters, key factors in final void decisionmaking. 


\section{Conclusion}

A pit lake prediction tool was developed to assess final voids for potential risks of interaction with groundwater and spilling to surface waters without the use of a daily time step WBM. In combination with adoption of a conservative wet/dry fluctuation, and the assessment of risk as a measurement of rain depth, the tool provides robust screening and quantification of these risks. This method provides more detail and a clearer communication of risk compared to currently accepted practices for final void assessments at BHP coal mines. Based on the screening of 21 final voids using the pit lake prediction tool, four of the final voids would be considered for detailed assessment under the BHP final void decision framework.

The screening tool uses a simple methodology that does not require specialised software or training. Model inputs including the final void catchment, land use delineation and stage storage curves are required for both methodologies. Both methodologies use the same AWBM runoff, evaporation pan factor and if required, groundwater inflows. The difference between the two methods is how the climate data is used to calculate the water level, a daily time step versus an annual average.

The pit lake prediction tool is therefore suitable for inclusion in long-term mine planning. If mine plans or modelling inputs are changed, the results can quickly be updated, without having to re-run models and process data.

The sensitivity analysis of the BHP parameters used in the assessment of final voids identified which inputs have the most influence on the long-term pit water levels. These assumptions are relevant to the BHP final voids considered in this study, but may not be applicable to other settings or site conditions. The following learnings and actions will be adopted for future assessments:

- The pit lake equilibrium water level is most sensitive to evaporation and runoff.

- There is a large range of uncertainty in AWBM runoff parameters applicable to coal mining. More work needs to be undertaken to develop site specific, calibrated AWBM parameters.

- In situations where groundwater inflow reduces to zero when the pit water level reaches the steady state groundwater level, it need not be included in the screening stage. However, the final void decision framework considers groundwater from other sources (i.e. basalt and alluvium aquifers) and for these cases, groundwater can be included in the pit lake prediction tool.

- In-pit spoil storage has a negligible impact on the equilibrium water level, but it does impact wet/dry fluctuation.

\section{Acknowledgement}

The authors thank BHP Coal Pty Ltd who funded this project, Gavin Rootsey (WRM Water \& Environment) for discussing the development of the pit lake prediction tool and the paper reviewer David Newton (WRM Water \& Environment).

\section{References}

Ball, J, Babister, M, Nathan, R, Weeks, W, Weinmann, E, Retallick, M \& Testoni, I, 2016, Australian Rainfall and Runoff (ARR): A Guide to Flood Estimation, Commonwealth of Australia.

Boughton, WC 2004, 'The Australian Water Balance Model', Environmental Modelling and Software, October 2004, vol. 19, iss. 10, pp. 943-956.

Calder, IR \& Neal, C 1984, 'Evaporation from saline lakes: a combination equation approach', Hydrological Sciences Journal, vol. 29, pp. 89-97.

Commonwealth Scientific and Industrial Research Organisation (CSIRO) 2015, 'Climate Change in Australia', Information for Australia's Natural Resource Management Regions: Technical Report, CSIRO and Bureau of Meteorology.

GoldSim 2017, GoldSim Version 12 User's Guide Volume 1 \& 2, GoldSim Technology Group, Issaquah.

Hawkins, JW 2004, 'Some hydrologic properties of surface mine spoil in the Appalachian plateau', Proceedings America Society of Mining and Reclamation, pp. 860-878.

Hydro Engineering \& Consulting Pty Ltd (HEC) 2018, BHP Open Cut Coal Mines Final Void Water Balance, Sep 2018. 
McJannet, D, Hawdon, A, Van Niel, T, Boadle, D, Baker, B, Trefry, M \& Rea, I 2017, 'Measurements of evaporation from a mine void lake and testing of modelling approaches', Journal of Hydrology, vol. 555, pp.631-647, https://doi.org/10.1016/ j.jhydrol.2017.10.064

Mulder, JC 1997, Queensland Lake and Aerial Evaporation, Volume 1, Report 000302.PR/2, Department of Natural Resources, Brisbane.

The Department of Environment and Science (DES) 2018, SILO climate data, viewed June/July 2018, https://legacy.longpaddock.qld.gov.au/silo/

Worley Parsons 2013, 'North Star Mine pit lake assessment, water and solute modelling', Water Solutions, Perth. 
